\title{
In the search of a cause of Crohn's disease
}

\author{
Govind K. Makharia $\cdot$ Urvashi B. Singh
}

While the exact cause of Crohn's disease (CD) is not known, it is thought that chronic inflammation in $\mathrm{CD}$ results from an inappropriate and chronic activation of the innate and adaptive mucosal immune systems in a genetically susceptible host, and that enteric microflorae play a pivotal role in the initiation and maintenance of the disease. ${ }^{1}$ Organisms such as Pseudomonas maltophilia, Mycobacterium kansasii, Chlamydia trachomatis, Bacteroides fragilis, Listeria monocytogenes, Escherichia coli and Mycobacterium avium subspecies paratuberculosis (MAP) have been implicated and identified in the intestines of patients with CD; however, no other putative pathogenic organism except MAP causes a chronic granulomatous inflammation of the intestines in every other species in which it is present. ${ }^{2}$ Moreover, because of remarkable clinical, morphological and epidemiological similarity between intestinal tuberculosis (caused by Mycobacterium tuberculosis) and CD in humans and Johne's disease (caused by Mycobacterium avium paratuberculosis) in cattle, a mycobacterial pathogen is thought to be a causative organism of $\mathrm{CD}^{3-7}$ An association and causality of Helicobacter pylori with peptic ulcer disease revolutionized the treatment of peptic ulcers; similar implication of MAP as a cause of CD has raised hopes amongst physicians, microbiologists and basic scientists for the cure of this disease. ${ }^{8}$

In the first report almost 25 years back, Chiodini and colleagues isolated cell-wall deficient cells, called sphero-

Govind K. Makharia ${ }^{1}$ Urvashi B. Singh ${ }^{2}$

Departments of ${ }^{1}$ Gastroenterology and Human Nutrition, and

${ }^{2}$ Microbiology, All India Institute of Medical Sciences,

New Delhi 110 029, India

G Makharia $(\square)$

e-mail: govindmakharia@gmail.com;

govindmakharia@aiims.ac.in

(C) Indian Society of Gastroenterology 2009 plasts, from tissue samples after several months of incubation from patients with CD. These spheroplasts were sub-cultured and they later developed a cell wall that stained positively with Ziehl-Neelson staining; they were classified as mycobacterial like organisms. ${ }^{9-11}$ These isolates were later confirmed as $M$. avium paratuberculosis by DNA hybridization. The unusual nature of the cell walldeficient MAP and the challenges in culture of MAP with its fastidious and slow growing requiring months to years to culture and multiple studies reporting failure to culture MAP from patients with CD dampened the initial zeal. ${ }^{12}$ There was then a period of silence in the 1990s. With availability of better culture techniques and use of molecular techniques to identify MAP in 2000s, there was resurgence of interest of many laboratories in this field. There has been a flurry of publications since then relating CD and MAP. ${ }^{13-25}$

MAP infection in humans is difficult to detect. The organisms are intracellular and minimize their own immune recognition. They are therefore difficult to isolate and propagate in culture and are relatively resistant to chemical and enzymatic lysis. Reliable access to their DNA is only achieved during sample processing by combining exposure to stringent lysis buffers with an additional optimised mechanical disruption step. Freezing samples and tissue extracts especially at $-20^{\circ} \mathrm{C}$ substantially reduces the PCR detection rate of their GC-rich DNA. The identification of MAP in patients with CD can be done by several different techniques such as culture of MAP from the intestines and blood; PCR amplification of blood or intestinal biopsies using IS900 DNA, a sequence specific for MAP; in-situ hybridization in tissues using IS900 sequence; serological tests using MAP specific antigens and direct visualization of MAP by light microscopy. ${ }^{4,26}$ According to a meta-analysis, compared with individuals free of IBD, the pooled odds ratio (OR) of those with $\mathrm{CD}$ having MAP was $7.01(95 \%$ CI 3.95-12.4) using PCR in tissue and 1.72 (1.02-2.90) in studies using ELISA in the serum. ${ }^{27}$ According to another recent meta-analysis, MAP was detected more frequently from patients with CD compared with those with ulcerative colitis (risk difference $0.19,95 \% \mathrm{CI}, 0.10-0.28$ ). ${ }^{28}$ 
In the present issue of the Journal, Sasikala et al. ${ }^{29}$ have shown that none of their 81 patients with $C D$ and 85 controls had MAP-DNA in intestinal biopsies using MAPspecific IS900. Similar results have also been reported from another center. ${ }^{30}$

The inconsistency of findings across different studies, using methods that are prone to technical variability, continues to be a major impediment to a definitive assessment of the role of MAP in CD. It is worth noting that in-house PCR in the tuberculosis laboratories are prone to error, in part because of the many methodological variances between laboratories such as DNA extraction protocols, adequate removal of tissue inhibitors, variable PCR conditions (direct PCR vs. nested PCR, differing number of cycles and extension times, etc.) and amplicon detection methods. ${ }^{31}$ There are two other reasons which can hamper the sensitivity of PCR for MAP-related infections: (i) the cell wall is very thick and hard to lyse, and (ii) the organism is buoyant and therefore resists concentration by centrifugation. ${ }^{3,32}$

The strength of the association as shown by two metaanalyses and consistent detection of MAP-DNA by many groups does not prove causality, and may arise from prior ingestion of nonviable organisms in water or milk. However, the detection of MAP-DNA in blood of patients with CD may suggest that a viable form of the organism is present in them. ${ }^{33,34}$ The presence of MAP in blood may also be a reflection of an increase in intestinal permeability which is seen in $40 \%$ of patients with CD. ${ }^{35}$ However, the more frequent detection of MAP in CD compared with UC argues against increased gut permeability as the sole explanation. ${ }^{27}$ Before we say that MAP is the cause of CD, MAP has to meet the Koch's postulates for microbial causation. ${ }^{36}$ There are some preliminary data that suggest that MAP has partially fulfilled the Koch's postulates. There are also evidences that we are exposed to MAP through our environment. MAP has been isolated from pasteurized milk infant formula made from pasteurized milk, breast milk from women with $\mathrm{CD}$, surface water, soil, cow manure "lagoons" that can leach into surface water, and municipal tap water, providing multiple routes of transmission to humans. ${ }^{4,37-39}$

While there are many protagonists who believe that MAP may be a cause of $\mathrm{CD}$, there are many who argue against the association. First, farmers and rural dwellers should be at increased risk of a livestock-associated pathogens, yet there is no evidence that they have increased rates of CD. ${ }^{40}$ Secondly, environmental conditions, such as poor sanitation and overcrowding which should favour transmission of an infection, actually appear to protect against CD. Thirdly, immunosuppressive drugs and anti-tumor necrosis factor- $\alpha$ should be associated with increased rates and severity of mycobacterial diseases, rather than improvement in the disease. ${ }^{41}$

The protagonists defend objections in many ways. We are not aware of the best staining technique for MAP. The organism that causes cat scratch disease, Bartonella henselae, was not seen under the microscope until researchers finally thought to try the Warthin-Starry silver stain on diseased lymph nodes almost 30 years after the disease was first described. ${ }^{42}$ While now "easily", seen by the usual Hematoxylin \& Eosin stain, Helicobacter pylori were visualized by the Warthin-Starry silver stain in Warren and Marshall's first report. ${ }^{43}$ All the available histochemical stains have not been tried to stain MAP in histological specimens of patients with CD. Most studies have used mucosal biopsies from the lesions or blood for showing MAP using various techniques described above. Mucosal biopsies generally are superficial and surrounded by necrosis and exudation; MAP may not be present in sufficient numbers in the superficial layers of intestine and may thus skip detection. It is possible that MAP is more often present in deeper layers of the intestine, and the fistulous tracts. One of the very important pathological features of CD is creeping fat in the mesentery which is not seen in other inflammatory conditions. The mesenteric fat may also be a good site to look for MAP. ${ }^{44}$ To say that MAP is somehow "harmless to man", we will have to prove that and they are present in human as a bystander, once it is well known that MAP causes chronic inflammation of the intestines in many cattles, and even in subhuman primates.

The present study has included relatively large number of patients with $\mathrm{CD}$. A negative association between $\mathrm{CD}$ and MAP as reported by the authors raises a question that in a tuberculosis endemic country, is MAP less prominent? Does $M$. tuberculosis or any other intestinal infection inhibit MAP? Before we believe this, such data needs to be replicated at other centers. There is another concern related with the duration of the disease included in this study. Most patients with $\mathrm{CD}$ reporting to tertiary care centers have a disease spanning over a long period of time,${ }^{45,46}$ the duration of symptoms in this study is relatively short (mean 8 months). It may not be wise to conclude, as the authors of this study have concluded, that MAP is not the cause of CD in India, especially once there are evidences from other parts of the world. If MAP is the cause or not the cause of CD, it will not vary according to country or even continent.

The failure of the anti-MAP drug trial (clarithromycin, rifabutin, and clofazimine) from Australia beyond sixteen weeks may not be taken as the final evidence against an association between MAP and CD. ${ }^{47,48}$ We do not exactly know the anti-MAP drugs, the best combination regimen, and the duration of the therapy. ${ }^{49}$ It is just a beginning of the process, the evidences either for or against have started pouring in. We will have to work and connect evidences into a complete story.

The remarkable work by Barry Marshall and Robin Warren led to a change in the concept and more importantly treatment of peptic ulcers. Despite many arguments against it, MAP stands tall as a candidate pathogen for CD. Gastroenterologists, microbiologists, pathologists, surgeons, and 
basic scientists should join hands and try find out the exact cause of this crippling disease.

\section{References}

1. Sartor RB. Mechanisms of disease: pathogenesis of Crohn's disease and ulcerative colitis. Nat Clin Pract Gastroenterol Hepatol 2006;3:390-407.

2. Eckburg PB, Relman DA. The role of microbes in Crohn's disease. Clin Infect Dis 2007;44:256-62.

3. Cocito C, Gilot P, Coene M, de Kesel M, Poupart P, Vannuffel P. Paratuberculosis. Clin Microbiol Rev 1994;7: $328-45$.

4. Greenstein RJ. Is Crohn's disease caused by a mycobacterium? Comparisons with leprosy, tuberculosis, and Johne's disease. Lancet Infect Dis 2003;3:507-14.

5. Sartor RB. Does Mycobacterium avium subspecies paratuberculosis cause Crohn's disease? Gut 2005;54:896-8.

6. Chacon O, Bermudez LE, Barletta RG. Johne's disease, inflammatory bowel disease, and Mycobacterium paratuberculosis. Annu Rev Microbiol 2004;58:329-63.

7. Greenstein RJ, Collins MT. Emerging pathogens: is Mycobacterium avium subspecies paratuberculosis zoonotic? Lancet 2004;364:396-7.

8. Ford A, Delaney B, Forman D, Moayyedi P. Eradication therapy for peptic ulcer disease in Helicobacter pylori positive patients. Cochrane Database Syst Rev 2004;4:CD003840.

9. Chiodini RJ, Van Kruiningen HJ, Thayer WR, Merkal RS, Coutu JA. Possible role of mycobacteria in inflammatory bowel disease. I. An unclassified Mycobacterium species isolated from patients with Crohn's disease. Dig Dis Sci 1984;29:1073-9.

10. Chiodini RJ, Van Kruiningen HJ, Thayer WR, Coutu JA, Merkal RS. In vitro antimicrobial susceptibility of a Mycobacterium sp. isolated from patients with Crohn's disease. Antimicrob Agents Chemother 1984;26:930-2.

11. Chiodini RJ, Van Kruiningen HJ, Merkal RS, Thayer WR Jr, Coutu JA. Characteristics of an unclassified Mycobacterium species isolated from patients with Crohn's disease. J Clin Microbiol 1984;20:966-71.

12. Graham DY, Markesich DC, Yoshimura HH. Mycobacteria and inflammatory bowel disease. Results of culture. Gastroenterology 1987;92:436-42.

13. Naser SA, SchwartzD, Shafran I. Isolation of Mycobacterium avium subsp paratuberculosis from breast milk of Crohn's disease patients. Am J Gastroenterol 2000;95:1094-5.

14. Bull TJ, Hermon-Taylor J, Pavlik I, El-Zaatari F, Tizard M. Characterization of IS900 loci in Mycobacterium avium subsp. Paratuberculosis and development of multiplex PCR typing. Microbiology 2000;146:2185-97.

15. Whittington RJ, Hope AF, Marshall DJ, Taragel CA, Marsh I. Molecular epidemiology of Mycobacterium avium subsp. paratuberculosis: IS900 restriction fragment length polymorphism and IS1311 polymorphism analyses of isolates from animals and a human in Australia. J Clin Microbiol 2000;38:3240-8.

16. Sechi LA, Mura M, Tanda F, et al. Identification of Mycobacterium avium subsp. paratuberculosis in biopsy specimens from patients with Crohn's disease identified by in situ hybridization. J Clin Microbiol 2001;39:4514-7.

17. Roholl PJ, Herrewegh A, van Soolingen D. Positive IS900 in situ hybridization signals as evidence for role of Mycobacterium avium subsp. paratuberculosis in etiology of Crohn's disease. J Clin Microbiol 2002;40:3112.

18. Naser SA, Shafran I, Schwartz D, El-Zaatari F, Biggerstaff J. In situ identification of mycobacteria in Crohn's disease patient tissue using confocal scanning laser microscopy. Mol Cell Probes 2002;16:41-8.

19. Bull TJ, McMinn EJ, Sidi-Boumedine K, et al. Detection and verification of Mycobacterium avium subsp. paratuberculosis in fresh ileocolonic mucosal biopsy specimens from individuals with and without Crohn's disease. J Clin Microbiol 2003;41:2915-23.

20. Naser SA, Ghobrial G, Romero C, Valentine JF. Culture of Mycobacterium avium subspecies paratuberculosis from the blood of patients with Crohn's disease. Lancet 2004;364:1039-44.

21. Sechi LA, Scanu AM, Molicotti P, et al. Detection and Isolation of Mycobacterium avium subspecies paratuberculosis from intestinal mucosal biopsies of patients with and without Crohn's disease in Sardinia. Am J Gastroenterol 2005;100:1529-36.

22. Autschbach F, Eisold S, Hinz U, et al. High prevalence of Mycobacterium avium subspecies paratuberculosis IS900 DNA in gut tissues from individuals with Crohn's disease. Gut 2005;54:944-9.

23. Romero C, Hamdi A, Valentine JF, Naser SA. Evaluation of surgical tissue from patients with Crohn's disease for the presence of Mycobacterium avium subspecies paratuberculosis DNA by in situ hybridization and nested polymerase chain reaction. Inflamm Bowel Dis 2005;11: 116-25.

24. Bentley RW, Keenan JI, Gearry RB, Kennedy MA, Barclay ML, Roberts RL. Incidence of Mycobacterium avium subspecies paratuberculosis in a population-based cohort of patients with Crohn's disease and control subjects. Am J Gastroenterol 2008;103:1168-72.

25. Singh AV, Singh SV, Makharia GK, Singh PK, Sohal JS. Presence and characterization of Mycobacterium avium subspecies paratuberculosis from clinical and suspected cases of Crohn's disease and in the healthy human population in India. Int J Infect Dis 2008;12:190-7.

26. Semret M, Turenne CY, Behr MA. Insertion sequence IS900 revisited. J Clin Microbiol 2006;44:1081-3.

27. Abubakar I, Myhill D, Aliyu SH, Hunter PR. Detection of Mycobacterium avium subspecies paratuberculosis from patients with Crohn's disease using nucleic acid-based techniques: a systematic review and meta-analysis. Inflamm Bowel Dis 2008;14:401-10.

28. Feller M, Huwiler K, Stephan R, et al. Mycobacterium avium subspecies paratuberculosis and Crohn's disease: a systematic review and meta-analysis. Lancet Infect Dis 2007;7:607-13.

29. Sasikala M, Reddy DN, Pratap N, et al. Absence of Mycobacterium avium ss paratuberculosis-specific IS900 sequence in intestinal biopsy tissues of Indian patients with Crohn's disease. Indian J Gastroenterol 2009;28: 169-74. 
30. Parrish NM, Radcliff RP, Brey BJ, et al. Absence of mycobacterium avium subsp. paratuberculosis in Crohn's patients. Inflamm Bowel Dis 2009;15:558-65.

31. Flores LL, Pai M, Colford JM Jr, Riley LW. In-house nucleic acid amplification tests for the detection of Mycobacterium tuberculosis in sputum specimens: meta-analysis and metaregression. BMC Microbiol 2005;5:55.

32. Chiodini RJ. Crohn's disease and the mycobacterioses: a review and comparison of two disease entities. Clin Microbiol Rev 1989;2:90-117.

33. Mendoza JL, Lana R, Díaz-Rubio M. Mycobacterium avium subspecies paratuberculosis and its relationship with Crohn's disease. World J Gastroenterol 2009;15:417-22.

34. Liu Y, van Kruiningen HJ, West AB, Cartun RW, Cortot A, Colombel JF. Immunocytochemical evidence of Listeria, Escherichia coli, and Streptococcus antigens in Crohn's disease. Gastroenterology 1995;108:1396-404.

35. Benjamin J, Makharia GK, Ahuja V, Kalaivani M, Joshi YK. Intestinal permeability and its association with the patient and disease characteristics in Crohn's disease. World J Gastroenterol 2008;14:1399-405.

36. Koch R. die Aetiologie der Tuberkulose. Mittbeilungen Kaisertichen Gesundbeitsamte 1884;2:I-88.

37. Pierce ES. Possible transmission of Mycobacterium avium subspecies paratuberculosis through potable water: lessons from an urban cluster of Crohn's disease. Gut Pathog 2009;1:17.

38. Lund BM, Gould GW, Rampling AM. Pasteurization of milk and the heat resistance of Mycobacterium avium subsp. paratuberculosis: a critical review of the data. Int J Food Microbiol 2002;77:135-45.

39. Waddell LA, Rajiæ A, Sargeant J, et al. The zoonotic potential of Mycobacterium avium spp. paratuberculosis: a systematic review. Can J Public Health 2008;99:145-55.
40. Jones PH, Farver TB, Beaman B, Cetinkaya B, Morgan KL. Crohn's disease in people exposed to clinical cases of bovine paratuberculosis. Epidemiol Infect 2006;134:49-56.

41. Behr MA, Kapur V. The evidence for Mycobacterium paratuberculosis in Crohn's disease. Curr Opin Gastroenterol 2008;24:17-21.

42. Wear DJ, Margileth AM, Hadfield TL, Fischer GW, Schlagel CJ, King FM. Cat scratch disease: a bacterial infection. Science 1983;221:1403-5.

43. Marshall BJ, Warren JR. Unidentified curved bacilli in the stomach of patients with gastritis and peptic ulceration. Lancet 1984;i:1311-5.

44. Pierce ES. Where are all the Mycobacterium avium subspecies paratuberculosis in patients with Crohn's disease? PLoS Pathog 2009;5:e1000234.

45. Amarapurkar DN, Patel ND, Rane PS. Diagnosis of Crohn's disease in India where tuberculosis is widely prevalent. World J Gastroenterol 2008;14:741-6.

46. Das K, Ghoshal UC, Dhali GK, Benjamin J, Ahuja V, Makharia GK. Crohn's disease in India: a multicenter study from a country where tuberculosis is endemic. Dig Dis Sci 2009;54:1099-107.

47. Selby W, Pavli P, Crotty B, et al. Antibiotics in Crohn's Disease Study Group. Two-year combination antibiotic therapy with clarithromycin, rifabutin, and clofazimine for Crohn's disease. Gastroenterology 2007;132:2313-9.

48. Lipton JE, Barash DP. Flawed Australian CD study does not end MAP controversy. Gastroenterology 2007; 133:1742.

49. Krishnan MY, Manning EJ, Collins MT. Comparison of three methods for susceptibility testing of Mycobacterium avium subsp. paratuberculosis to 11 antimicrobial drugs. $J$ Antimicrob Chemother 2009;64:310-6.

\section{Indian Journal of Gastroenterology J Mitra Memorial Award}

\section{The Indian Journal of Gastroenterology bestows this award for the best original scientific contribution published in the Journal during the year}

This award carries a prize of Rs 20000 , and will be given to the department(s) submitting the selected paper. The paper will be selected by a scientific committee appointed by the Editor, from among all the Original Articles published in the Journal during the year. In the event of a tie, the award will be distributed equally. Terms for eligibilty will apply.

The award has been made possible by a generous endowment from M/s J Mitra and Co Ltd, New Delhi. 